\title{
Substratos e teor de umidade para o teste de germinação de sementes de Apuleia leiocarpa (Vog.) Macbr.
}

\section{Substrates and moisture content for seed germination test of Apuleia leiocarpa (Vog.) Macbr.}

\author{
Matheus Santin Padilha ${ }^{1 *}$, Lúcia Salengue Sobral ${ }^{2}$, Carolina Riviera Duarte Maluche Baretta ${ }^{3}$, Lucilene de Abreu ${ }^{4}$
}

Resumo: O substrato e a quantidade de água utilizada são fatores determinantes para a condução do teste de germinação, afetando o crescimento do embrião e a formação da plântula. Com este trabalho objetivou-se identificar o tipo de substrato e o teor de umidade mais adequado para a realização do teste de germinação de sementes de Apuleia leiocarpa. Os tratamentos consistiram nos substratos: papel toalha (RP) e mata-borrão (SP), umedecidos com volumes de água equivalentes a 2,0; 2,5 e 3,0 vezes a massa do papel seco; areia (SA) e vermiculita (SV) umedecidos com quantidade de água correspondente a 50, 60 e $70 \%$ da sua capacidade de campo. Os testes foram conduzidos em germinador na temperatura constante de $25^{\circ} \mathrm{C}$. As variáveis avaliadas foram plântulas normais, plântulas anormais, primeira contagem de germinação, índice de velocidade de germinação, tempo médio de germinação e frequência relativa de germinação. $\mathrm{O}$ experimento foi conduzido em delineamento experimental inteiramente casualizado com três repetições de 50 sementes cada. A germinação das sementes não foi influenciada pelos volumes de água utilizados para umedecimento. Apenas os substratos apresentaram diferenças, sendo que o substrato papel toalha mostra-se adequado para o teste de germinação de sementes de Apuleia leiocarpa enquanto, o papel mata borrão não é recomendado para o teste de germinação desta espécie.

Palavras-chave: Embebição; Sementes florestais; Volume de água.

\begin{abstract}
The substrate and amount of water used are determinant factors for conducting the germination test, affecting the growth of the embryo and the formation of the seedling. The objective of this work was to identify the ideal substrate and the moisture content for the seed germination test of Apuleia leiocarpa. The treatments consisted of substrates: paper towels (RP) and blotter paper (SP), moistened with water volumes equivalent to $2.0 ; 2.5$ and 3.0 times the dry paper mass; sand (SA) and vermiculite (SV) moistened with an amount of water corresponding to 50, 60 and $70 \%$ of its field capacity. The germination tests were conducted in a constant temperature germinator of $25^{\circ} \mathrm{C}$. The variables under evaluation were normal seedlings, abnormal seedlings, first germination count, germination speed index, average germination time and relative germination frequency. The experiment was conducted in a completely randomized design with three replicates of 50 seeds. Seed germination was not influenced by the water volumes used. Only the substrates showed differences, and the paper towel substrate is better for the germination test of Apuleia leiocarpa seeds, while the blotter paper is not recommended for the germination test of this species.
\end{abstract}

Keywords: Inbibition; Forest seeds; Volume of water.

\footnotetext{
*Autor para correspondência

Recebido para publicação em 12/12/2017; aprovado em 25/09/2018

${ }^{1}$ Graduando em agronomia pela Universidade Comunitária da Região de Chapecó, Chapecó, Santa Catarina. E-mail: matheus_santin@hotmail.com.

${ }^{2}$ Mestre em Agronomia, docente da Universidade Comunitária da Região de Chapecó, Chapecó, Santa Catarina. E-mail: luciass@ unochapeco.edu.br

${ }^{3}$ Doutora em Agronomia, docente da Universidade Comunitária da Região de Chapecó, Chapecó, Santa Catarina. E-mail: carolmaluche@unochapeco.edu.br

${ }^{4}$ Doutora em Recursos Genéticos Vegetais, docente da Universidade Comunitária da Região de Chapecó, Santa Catarina. E-mail: labreu@unochapeco.edu.br
} 


\section{INTRODUÇÃO}

A Apuleia leiocarpa (vog.) Macbr. conhecida popularmente como grápia, garapa ou amarelinho, é uma espécie nativa da família Fabaceae e subfamília Caesalpinioideae, com dispersão desde o Nordeste brasileiro até o Uruguai e Argentina, habitando preferencialmente as encostas de morros e solos bem drenados (CARVALHO, 2003). É uma árvore de grande porte, que pode chegar a $40 \mathrm{~m}$ de altura e apresentar $60-100 \mathrm{~cm}$ de diâmetro a altura do peito. Tem um valor econômico significativo e fornece uma das dez melhores madeiras brasileiras, considerada resistente e durável (GRINGS; BRACK, 2011). Por esse motivo, foi muito utilizada na indústria moveleira, construção civil (tacos, assoalhos, palanques, aberturas e telhados), na produção de barris de cerveja, pipas e toneis de vinho e cachaça (LORENZI, 2008; GRINGS; BRACK, 2011). Devido a essas qualidades foi muito explorada, sendo atualmente considerada como espécie vulnerável a extinção, conforme a Portaria do Ministério do Meio Ambiente $n^{\circ} 443$, de 17 de dezembro de 2014 (BRASIL, 2014).

A partir da década de 80, a demanda por sementes florestais aumentou consideravelmente em função da necessidade de recuperação de áreas desmatadas e degradadas (SANTOS; AGUIAR, 2000). Porém, nas Regras para Análise de Sementes (BRASIL, 2009) as informações para a avaliação da germinação de espécies florestais nativas são restritas, sendo destacadas principalmente espécies exóticas. As metodologias existentes para realização do teste de germinação para espécies florestais nativas são incipientes se comparadas a espécies agrícolas. Entretanto, a partir do conhecimento gerado pela pesquisa foram elaboradas as Instruções para Análise de Sementes Florestais (BRASIL, 2013) que traz informações para realização do teste de germinação de diversas espécies, mas mesmo com essas informações é necessário o aperfeiçoamento das metodologias para definir protocolos para realização dos testes (LIMA JÚNIOR et al., 2011; FIGLIOLIA, 2015).

A normatização de procedimentos para o teste de germinação quanto à temperatura, luz, substrato, métodos de superação de dormência e duração do teste são fundamentais para obtenção de resultados reproduzíveis entre laboratórios, e a comparação do valor de diferentes lotes para a comercialização (MARCOS FILHO et al., 1987).

Dentre os fatores que afetam o processo de germinação, o substrato é essencial, uma vez que, fornece o suporte físico para as sementes e condições adequadas de água e oxigênio através de sua capacidade de retenção hídrica e aeração, respectivamente. Ainda, a escolha do substrato para a realização do teste de germinação deve levar em consideração, o tamanho da semente, sensibilidade à luz, necessidade hídrica da espécie e a facilidade para a avaliação e contagem das plântulas (BRASIL, 2009). Os substratos papel toalha, papel filtro, papel mata-borrão, solo e areia são indicados pelas Regras para Análise de Sementes (BRASIL, 2009) e, o substrato vermiculita é empregado com sucesso para espécies florestais nativas como Parapiptadenia rigida (MONDO et al., 2008), Caesalpinia pyramidalis (LIMA et al., 2011), Sebastiania brasiliensis (BASSACO et al., 2014), e seu uso é indicado pelas Instruções para Análise de Sementes Florestais (BRASIL, 2013).

Ao mesmo tempo, a disponibilidade de água do substrato é um fator decisivo para desencadear o processo germinativo, contribuindo para a reidratação dos tecidos da semente, favorecendo o amolecimento e ruptura do tegumento, difusão gasosa e ativação enzimática, que permite a digestão, translocação dos nutrientes armazenados para o crescimento do eixo embrionário e emergência da radícula (MARCOS FILHO, 2015). Desta maneira, é necessário o fornecimento de água adequado, uma vez que, tanto o excesso quanto a deficiência de água afetam o processo de germinação de forma negativa (BORGES; TOOROP, 2015).

$\mathrm{Na}$ literatura, encontram-se pesquisas avaliando os substratos e o teor de umidade para o teste de germinação de sementes florestais nativas com espécies como a Dinizia excelsa (VARELA et al., 2005), Caesalpinia echinata (MELLO; BARBEDO, 2007), Amburana cearensis (GUEDES et al., 2010), Stryphnodendron adstringens (MARTINS et al., 2011), Chorisia glaziovii (GUEDES; ALVES, 2011), Melanoxylon brauna (FLORES et al., 2013), Combretum leprosum (PACHECO et al., 2014), Parkia platycephala (GONÇALVES et al., 2015), Simira gardneriana (OLIVEIRA et al., 2016). No entanto, o cenário das pesquisas com a exigência de água para o processo de germinação de sementes de espécies florestais ainda é incipiente, porém, são de grande importância, pois contribuem para aperfeiçoar os métodos de condução dos testes de germinação dos laboratórios, evitando a discrepância entre os resultados (RAMOS et al., 2006a, b).

Para Apuleia leiocarpa é necessário maior detalhamento sobre os procedimentos para condução do teste de germinação para esta espécie em relação aos substratos e ao volume de água a ser utilizado, sendo esse último não explorado na literatura. Estudos dessa natureza buscam elucidar as causas das discrepâncias que ocorrem entre os resultados obtidos entre lotes de sementes da mesma espécie. Diante do exposto, o objetivo do presente trabalho foi identificar o tipo de substrato e o teor de umidade mais adequado para a realização do teste de germinação de sementes de Apuleia leiocarpa.

\section{MATERIAL E MÉTODOS}

O experimento foi conduzido no Laboratório de Análise de Sementes da Universidade Comunitária da Região de Chapecó (Unochapecó), com sementes de Apuleia leiocarpa (Vog.) Macbr., coletadas de sete árvores matrizes localizadas em um remanescente florestal no Distrito de Marechal Borman [ $27^{\circ} 10^{\prime} 42^{\prime}$ 'S e $\left.52^{\circ} 39^{\prime \prime} 52^{\prime \prime} \mathrm{W}\right]$, zona rural de Chapecó (SC), no mês de março de 2016. O município possui altitude de $670 \mathrm{~m}$, clima da região do tipo mesotérmico úmido com verão quente $(C f a)$, conforme a classificação de Köppen (ALVARES et al., 2013).

Após a coleta, os frutos foram beneficiados de forma manual, realizando-se a abertura dos mesmos, extração das sementes e eliminação do material inerte, sementes imaturas e danificadas. As sementes ficaram armazenadas em câmara seca $\left(18^{\circ} \mathrm{C}\right.$ e $50 \%$ de umidade) por 15 dias até o início dos testes.

O teste de germinação foi instalado em germinador tipo Mangelsdorf com regime de luz constante e temperatura de $25^{\circ} \mathrm{C}$ (BRASIL, 2013). Para a superação da dormência as sementes foram submetidas à imersão em ácido sulfúrico $\left(\mathrm{H}_{2} \mathrm{SO}_{4}\right)$ concentrado $(95-97 \%)$ por cinco minutos (BIANCHETTI et al., 1995), seguidas de lavagem em água corrente para remoção do resíduo por um minuto e secagem por 15 minutos sobre papel toalha. 
Os substratos utilizados foram papel mata-borrão, papel toalha, areia (esterilizada e peneirada em malha $0,84 \mathrm{~mm}$ ) e vermiculita (granulometria fina). Os substratos papel toalha e papel mata-borrão foram umedecidos com volumes de água de 2,0; 2,5 e 3,0 vezes a massa do papel seco (MPS). Os substratos areia e vermiculita foram umedecidos com volume de água equivalente a 50,60 e 70\% da capacidade de campo (CC). Os substratos foram umedecidos apenas no inicio do teste, não sendo realizado umedecimento durante o período do experimento.

O papel mata-borrão, areia e vermiculita foram acondicionados em caixas tipo "gerbox" e a semeadura foi efetuada sobre papel (SP), sobre areia (SA) e sobre vermiculita $(\mathrm{SV})$, respectivamente. Para o substrato papel toalha a semeadura foi realizada na forma de rolo de papel (RP). Os tratamentos foram distribuídos conforme delineamento experimental inteiramente casualizado com 12 tratamentos e três repetições de 50 sementes para cada tratamento.

Para avaliar o efeito dos substratos sobre a germinação das sementes as variáveis avaliadas foram: primeira contagem de germinação, porcentagem de plântulas normais (germinação), porcentagem de plântulas anormais, Índice de Velocidade de Germinação (IVG) e Tempo Médio de Germinação (TMG).

A primeira contagem de germinação foi realizada no sétimo dia após a instalação do teste de germinação, contabilizando as plântulas normais presentes. Para a avaliação da porcentagem de plântulas normais (germinação) foram realizadas contagens diárias até o fim do experimento. Foram consideradas como plântulas normais, aquelas que possuíam todas as estruturas essenciais (raiz primária, hipocótilo, epicótilo, cotilédones e plúmula) e que apresentavam quatro centímetros de comprimento. Além das plântulas normais, foram avaliadas as plântulas anormais de acordo às prescrições das Regras para Análise de Sementes (BRASIL, 2009).

O cálculo do Índice de Velocidade de Germinação (IVG) foi realizado pelo somatório do número de plântulas normais (Gi) obtidas a cada dia, dividido pelo número de dias (Ni) decorridos entre a semeadura e a germinação conforme a
Equação (1) proposta por Maguire (1962):

$\mathrm{IVG}=\sum\left(\mathrm{G}_{\mathrm{i}}\right) /\left(\sum \mathrm{N}_{\mathrm{i}}\right)$

O Tempo Médio de Germinação (TMG) foi expresso em dias e calculado através da Equação (2) proposta por Labouriau, (1983):

$\mathrm{TMG}=\sum\left(\mathrm{n}_{\mathrm{i}} \mathrm{t}_{\mathrm{i}}\right) /\left(\sum \mathrm{n}_{\mathrm{i}}\right)$

em que: $n_{i}$ é número de sementes germinadas no intervalo entre cada contagem e $t_{i}$, o tempo decorrido entre o início da germinação e a i-ésima contagem.

A Frequência Relativa de Germinação (Fr) foi expressa em porcentagem e calculada pelo número de sementes germinadas por dia (ni), dividido pelo somatório do número total de sementes germinadas ( $\Sigma$ ni), conforme Equação (3) de Labouriau e Valadares (1976):

$$
\operatorname{Fr}=\left(\mathrm{n}_{\mathrm{i}} / \sum \mathrm{n}_{\mathrm{i}}\right) 100
$$

Os resultados foram submetidos à análise de variância (teste F) utilizando-se o software estatístico Assistat versão 7.7 (SILVA; AZEVEDO, 2016), sendo que, os dados expressos em porcentagem foram transformados pela fórmula $\mathrm{Y}=\operatorname{arc} \operatorname{sen} \sqrt{\% / 100}$ para atendimento à normalidade. A comparação entre as médias foi efetuada através do teste de Scott-Knott a 5\% de probabilidade.

\section{RESULTADOS E DISCUSSÃO}

As sementes de Apuleia leiocarpa apresentavam no momento da condução do experimento grau de umidade de $11,3 \%$ e, para todas as variáveis avaliadas, houve efeito significativo pelo teste de Scott-Knott a 5\% de probabilidade.

Os resultados demonstram que a porcentagem de plântulas normais (Tabela 1) foi superior nos substratos papel toalha, areia e vermiculita, quando comparada à obtida no papel mata-borrão, o qual apresentou número de plântulas anormais, significativamente superior. Em todos os substratos as plântulas anormais caracterizaram-se pelo não desenvolvimento do hipocótilo e da plúmula. O lote de sementes utilizado apresentou porcentagem de plântulas normais superiores a $80 \%$. Estes resultados são semelhantes aos obtidos por Wielewicki et al. (2006) e Fellipi et al. (2012), demonstrando que os lotes de sementes de Apuleia leiocarpa podem apresentar germinação próximas ou acima de $80 \%$.

Tabela 1. Porcentagem de plântulas normais, plântulas anormais e, primeira contagem de germinação de sementes de Apuleia leiocarpa obtidos para os substratos areia (SA), vermiculita (SV), papel toalha (RP) e papel mata-borrão (SP) com os diferentes volumes de água testados [50, 60 e 70\% da capacidade de campo (CC) e 2,0; 2,5 e 3,0 vezes a massa de papel seco (MPS)]

\begin{tabular}{lccc}
\multicolumn{1}{c}{ Tratamentos } & Plântulas Normais (\%) & Plântulas Anormais (\%) & Primeira Contagem (\%) \\
\hline Areia (SA) /50\% CC & $94 \mathrm{a}^{*}$ & $4 \mathrm{~b}$ & $4 \mathrm{~b}$ \\
Areia (SA) /60\% CC & $89 \mathrm{a}$ & $4 \mathrm{~b}$ & $11 \mathrm{~b}$ \\
Areia (SA) /70\% CC & $93 \mathrm{a}$ & $5 \mathrm{~b}$ & $25 \mathrm{~b}$ \\
Papel toalha (RP) /2,0 vezes MPS & $92 \mathrm{a}$ & $4 \mathrm{~b}$ & $70 \mathrm{a}$ \\
Papel toalha (RP) /2,5 vezes MPS & $91 \mathrm{a}$ & $1 \mathrm{~b}$ & $71 \mathrm{a}$ \\
Papel toalha (RP) /3,0 vezes MPS & $90 \mathrm{a}$ & $8 \mathrm{~b}$ & $65 \mathrm{a}$ \\
Vermiculita (SV) /50\% CC & $90 \mathrm{a}$ & $3 \mathrm{~b}$ & $5 \mathrm{~b}$ \\
Vermiculita (SV) /60\% CC & $92 \mathrm{a}$ & $6 \mathrm{~b}$ & $5 \mathrm{~b}$ \\
Vermiculita (SV) /70\% CC & $88 \mathrm{a}$ & $5 \mathrm{~b}$ & $0 \mathrm{~b}$ \\
Papel mata-borrão (SP) /2,0 vezes MPS & $69 \mathrm{~b}$ & $0 \mathrm{~b}$ \\
Papel mata-borrão (SP) /2,5 vezes MPS & $68 \mathrm{~b}$ & $20 \mathrm{a}$ & $0 \mathrm{~b}$ \\
Papel mata-borrão (SP) /3,0 vezes MPS & $61 \mathrm{~b}$ & $22 \mathrm{a}$ & $0 \mathrm{~b}$ \\
\hline CV (\%) & 15,2 & $24 \mathrm{a}$ & 43,2 \\
\hline
\end{tabular}

*Médias seguidas pela mesma letra na coluna não diferem entre si pelo teste de Scott-Knott $(\mathrm{P}<0,05)$.

Para o substrato papel mata-borrão, a porcentagem de plântulas normais e de primeira contagem de germinação foram afetadas de forma negativa (Tabela 1). A menor superfície de contato que o substrato papel mata-borrão 
oferece às sementes, pode ter resultado em redução da absorção de água e reidratação dos tecidos, como também verificado para Chorisia glaziovii (GUEDES; ALVES, 2011) e Peltophorum dubium (ALVES et al., 2011). Diferente dos resultados obtidos, José et al., (2011) avaliando substratos na germinação de Apuleia leiocarpa verificou que o substrato papel toalha na forma de rolo umedecido a 3,0 vezes a massa do papel seco apresentou resultados de germinação superiores ao substrato areia umedecido com $60 \%$ da capacidade de campo na temperatura de $25^{\circ} \mathrm{C}$.

A primeira contagem de germinação (Tabela 1) ocorreu aos sete dias após a montagem do teste para todos os tratamentos, com exceção do tratamento papel mata-borrão que iniciou a sua germinação aos 12 dias de avaliação. O papel toalha apresentou maior porcentagem de primeira contagem de germinação e foi superior aos demais substratos. Para os substratos areia e vermiculita visualizava-se o início da emissão da radícula, enquanto no papel mata-borrão, as sementes se encontravam embebidas, sem indicativo de emissão da radícula.

Para Popinigis (1985) a primeira contagem de germinação é uma forma de avaliar as diferenças no vigor em lotes de sementes. Nesse sentido, o substrato papel toalha em forma de rolo favoreceu a expressão do vigor das sementes de Apuleia leiocarpa, isso pode estar relacionado à maior superfície de contato que o rolo de papel proporciona, já que a condução do teste para os demais substratos foi realizada sobre areia, sobre papel e sobre vermiculita. Resultados semelhantes foram obtidos por Alves et al. (2011), onde as sementes de Peltophorum dubium apresentaram maior porcentagem de primeira contagem de germinação quando o teste foi realizado em papel toalha na forma de rolo, sendo superior ao substrato papel mata-borrão e vermiculita.

O uso de diferentes volumes de água no substrato não revelou efeito sobre as variáveis plântulas normais (Tabela 1). Corroborando com os resultados, Gonçalves et al. (2015) verificaram que o umedecimento do substrato papel toalha com teores de água equivalentes a 2,0; 2,5; 3,0 e 3,5 vezes o seu peso seco, nas temperaturas de 25,30 e $20-30^{\circ} \mathrm{C}$, não influenciaram a germinação de sementes de Parkia platycephala, entretanto, obtiveram que o volume de água no substrato, influenciou a primeira contagem de germinação, em que, volume de água de 2,5 e 3,0 vezes a massa do papel seco apresentou maior porcentagem de primeira contagem de germinação. Contudo, segundo Ramos et al. (2006a) o volume de água utilizado no substrato influenciou a germinação sementes de Schizolobium amazonicum em que a germinação foi favorecida na umidade equivalente a 2,5 e 3,0 vezes a massa do papel seco. Resultado semelhante foi observado por Ochroma pyramidale, porém com volume de água correspondente a 1,5 vezes a massa do papel seco (RAMOS et al., 2006b). Tais resultados indicam que algumas espécies toleram uma maior faixa de umidade em relação ao volume de água presente no substrato.

Em relação aos substratos areia e vermiculita, Mendes et al. (2010) avaliando a germinação de sementes de Ochroma pyramidale, verificaram que o uso de volumes de água de 60 , 70,80 e $90 \%$ para os substratos areia e vermiculita não influenciou o processo de germinação. As Instruções para Análise de Sementes Florestais (BRASIL, 2013) indicam que o substrato vermiculita seja umedecido entre 0,5 e 2,0 vezes a sua massa seca em água, entretanto, verifica-se que o uso do método de capacidade de campo, pode ser utilizado para umedecimento do substrato vermiculita, como observado para Luehea divaricata (DUTRA et al., 2016), Parapiptadenia rigida (MONDO et al., 2008) e Caesalpinia pyramidalis (LIMA et al., 2011).

Pesquisadores comprovaram que diferentes espécies dentro da mesma família botânica tem o processo germinativo favorecido em mais de um substrato. Melhores resultados de germinação foram observados para Dalbergia nigra (ANDRADE et al., 2006) em papel toalha e vermiculita e para Caesalpinia pyramidalis em areia e vermiculita (LIMA et al., 2011), nesse sentido a porcentagem de germinação superior nos substratos areia, papel toalha e vermiculita para Apuleia leiocarpa, pode estar relacionado a sua adaptação a diferentes condições de solos como relatado por Grings e Brack (2011).

Os resultados de IVG (Tabela 2) demonstraram que os substratos areia, papel toalha e vermiculita, em todos os volumes de água utilizados para o umedecimento apresentaram maior IVG em relação ao papel mata-borrão. Contudo, com exceção do substrato papel mata-borrão, não se verificou diferença significativa entre os substratos areia, papel toalha e vermiculita.

Tabela 2. Índice de velocidade de germinação (IVG) e tempo médio de germinação (TMG) de sementes de Apuleia leiocarpa obtidos para os substratos areia (SA), vermiculita (SV), papel toalha (RP) e papel mata-borrão (SP) com os diferentes volumes de água testados [50,60 e 70\% da capacidade de campo (CC) e 2,0; 2,5 e 3,0 vezes a massa de papel seco (MPS)].

\begin{tabular}{lcc}
\multicolumn{1}{c}{ Tratamentos } & IVG & TMG (dias) \\
\hline Papel toalha (RP) / 2,0 vezes MPS & $6,33 \mathrm{a}^{*}$ & $7,31 \mathrm{~b}$ \\
Papel toalha (RP) / 2,5 vezes MPS & $6,30 \mathrm{a}$ & $7,31 \mathrm{~b}$ \\
Papel toalha (RP) / 3,0 vezes MPS & $6,13 \mathrm{a}$ & $7,51 \mathrm{~b}$ \\
Areia (SA) / 50\% CC & $5,05 \mathrm{a}$ & $9,45 \mathrm{~b}$ \\
Areia (SA) / 60\% CC & $5,17 \mathrm{a}$ & $8,73 \mathrm{~b}$ \\
Areia (SA) / 70\% CC & $5,67 \mathrm{a}$ & $8,31 \mathrm{~b}$ \\
Vermiculita (SV) / 50\% CC & $9,67 \mathrm{~b}$ \\
Vermiculita (SV) / 60\% CC & $9,78 \mathrm{a}$ \\
Vermiculita (SV) / 70\%CC & $9,88 \mathrm{a}$ \\
Papel mata-borrão (SP) / 2,0 vezes MPS & $9,83 \mathrm{~b}$ \\
Papel mata-borrão (SP) / 2,5 vezes MPS & $4,58 \mathrm{a}$ & $22,54 \mathrm{a}$ \\
Papel mata-borrão (SP) / 3,0 vezes MPS & $1,73 \mathrm{~b}$ & $22,79 \mathrm{a}$ \\
\hline
\end{tabular}

*Médias seguidas pela mesma letra na coluna não diferem entre si, pelo teste de Scott-Knott $(\mathrm{P}<0,05)$. 
Para a variável IVG, diferente dos resultados obtidos neste estudo, o substrato areia foi o que apresentou maior IVG para sementes de Chorisia glaziovii (GUEDES; ALVES, 2011) e Parkia multijuga (ROCHA et al., 2014). Em contrapartida, para algumas espécies florestais como Caesalpinia pyramidalis (LIMA et al., 2011) e Amburana cearensis (GUEDES et al., 2010), mais de um substrato favorece o IVG, sendo os substratos areia e papel toalha para Caesalpinia pyramidalis e, a areia e a vermiculita para Amburana cearensis.

Os menor IVG verificado para o substrato papel mataborrão também foi obtido por Alves et al. (2011) com sementes de Peltophorum dubium e por Alves et al. (2012) com sementes de Crataeva tapia. Possivelmente o substrato papel mata-borrão forneceu menor quantidade de água às sementes, prolongando a fase II do processo de germinação a qual depende do potencial hídrico do substrato, atrasando o processo germinativo, já que quanto menor o potencial hídrico do substrato maior é o tempo desta fase (MARCOS FILHO, 2015), resultando no menor IVG, maior TMG e, afetando a frequência da germinação (Figura 1), os quais são fatores preponderantes para a definição do substrato a ser utilizado. Entretanto, a escolha do substrato é dependente da espécie, pois para sementes de Simira gardneriana a velocidade de germinação foi prejudicada no papel mataborrão, papel toalha e vermiculita, e favorecida no substrato areia utilizando a temperatura de $25^{\circ} \mathrm{C}$ (OLIVEIRA et al., 2016).

O menor tempo de germinação é desejável quando se busca a definição de um substrato. Em condições de laboratório a germinação por períodos prolongados pode ser prejudicial, sendo que, pode ocorrer a ação de patógenos que afetam o processo de germinação (OLIVEIRA et al., 2015), além de ser indesejável para a rotina de laboratório. Dessa forma, os substratos que apresentaram menor tempo de germinação foram a areia, o papel toalha e a vermiculita (Tabela 2), os quais não diferiram entre si. Resultados semelhantes foram obtidos por Dutra et al. (2016), em que os substratos areia, papel toalha na forma de rolo e vermiculita não diferiram entre si para a variável TMG.

O substrato mais apropriado para cada espécie varia com as características das sementes a serem testadas (FERRAZ; CALVI, 2011). Dessa forma, diferente do obtido no presente estudo, o substrato areia favoreceu a redução do tempo de germinação para sementes de Caesalpinia ferrea (LIMA et al., 2006). Da mesma forma, o substrato papel toalha proporcionou uma germinação com menor TMG para sementes de Stryphnodendron adstringens (MARTINS et al., 2011) e Albizia edwallii (DUARTE et al., 2015). Visto a diferença de resultados em relação às espécies vegetais, vale ressaltar que são necessários estudos sobre o substrato adequado para o teste de germinação das espécies florestais, buscando a padronização das metodologias utilizadas para realização do teste.

A germinação foi distribuída de forma heterogênea nos substratos ao longo do tempo. A frequência relativa de germinação observada nos substratos papel toalha (Figura 1A), areia (Figura 1C) e vermiculita (Figura 1D) ocorre de forma regular e rápida; entretanto, no substrato papel mataborrão (Figura 1B), a frequência de germinação foi desuniforme e o teste de germinação prolongou-se até os 30 dias após a montagem do experimento. Tais resultados reforçam os valores encontrados para as variáveis IVG e TMG (Tabela 2).

Figura 1. Distribuição da frequência relativa de germinação (Fr) de sementes de Apuleia leiocarpa obtidos para os substratos areia (SA), vermiculita (SV), papel toalha (RP) e papel mata-borrão (SP) com os diferentes volumes de água testados [50, 60 e $70 \%$ da capacidade de campo (CC) e 2,0; 2,5 e 3,0 vezes a massa de papel seco (MPS)].

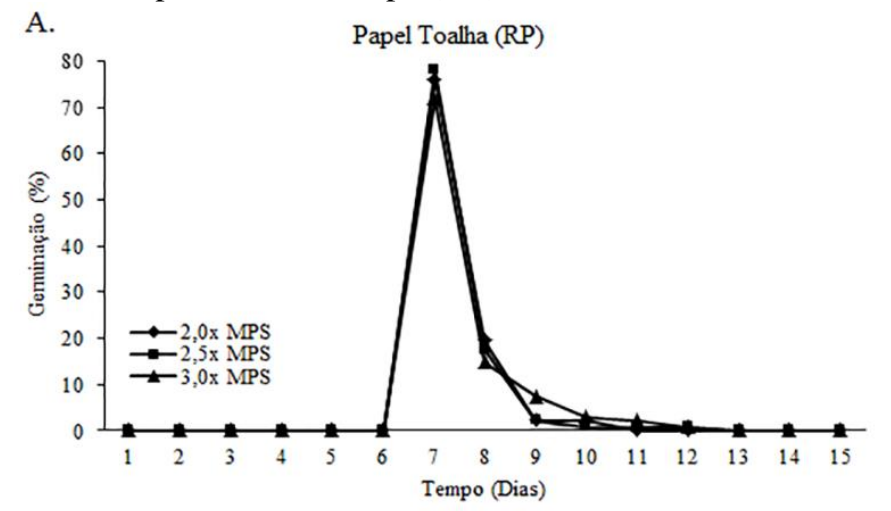

B.

Papel Mata-Borrão (SP)

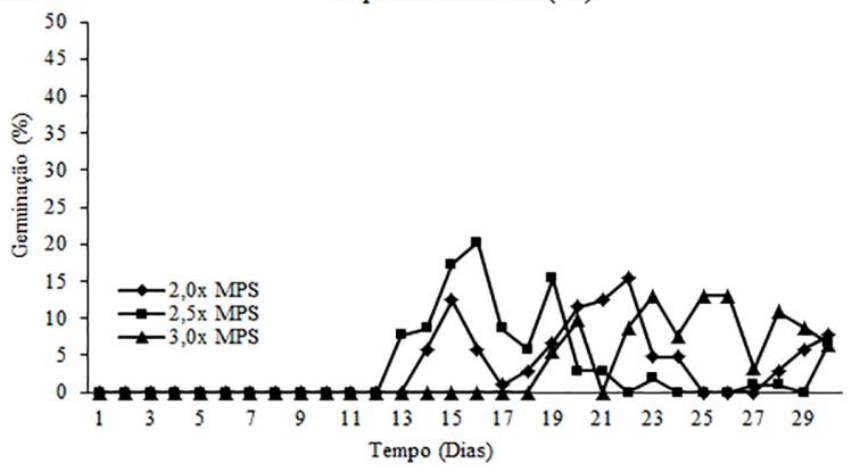

C.

Areia (SA)

D.
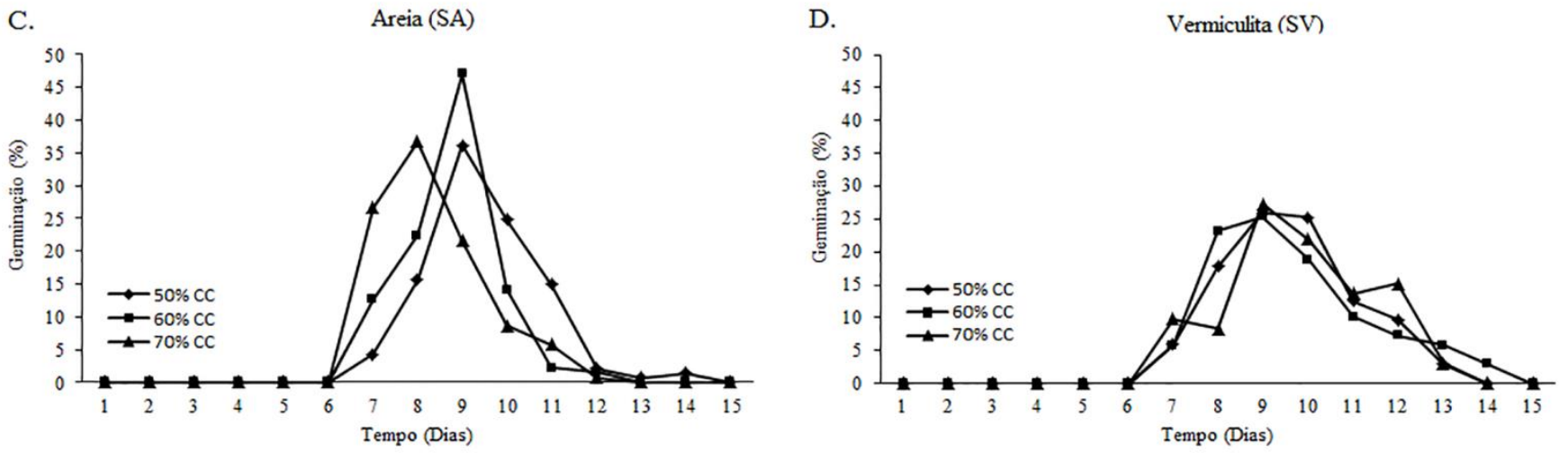

Revista Verde, v.13, n.4, p.437-444, 2018 
Os estudos relacionados à definição de protocolos para condução do teste de germinação de uma espécie têm sido realizados buscando condições que a germinação ocorra de forma regular, rápida e completa (BRASIL, 2009), nesse sentido, os substratos areia, papel toalha e vermiculita apresentaram resposta semelhante considerando os fatores desejados.

A desuniformidade e a menor velocidade do processo de germinação no substrato papel mata-borrão (Figura 1B) podem ser atribuídas a um efeito de estresse hídrico ocasionado pelo ressecamento do substrato, onde a partir do $10^{\circ}$ dia este substrato começou a demonstrar sinais de ressecamento, independente do volume de água adicionado, o que interferiu na germinação como verificados nos resultados já apresentados (Tabela 1). A umidade do substrato é essencial, visto que, quanto menor o potencial hídrico do substrato mais lento é o processo de germinação (BEWLEY et al., 2013), dessa forma Spadeto et al. (2012) avaliando à germinação de sementes de Apuleia leiocarpa em condições de restrição hídrica verificaram redução da germinação final e desuniformidade no processo de germinação. Resultados semelhantes foram alcançados por Martins et al. (2012) com sementes de Tabebuia chrysotricha.

Com os resultados de frequência relativa observa-se que a primeira contagem do teste de germinação de sementes de Apuleia leiocarpa utilizando o substrato papel toalha pode ser realizada aos sete dias e, com contagem final aos 12 dias. Os resultados obtidos no presente estudo divergem dos indicados pelas Instruções para Análise de Sementes Florestais (2013) em relação à contagem final do teste de germinação, em que, indicam realizar a contagem final do teste de Apuleia leiocarpa com 10 dias após a montagem do teste. Para os substratos areia e vermiculita observa-se que a primeira contagem pode ser realizada no sétimo dia e finalizada aos 14 dias após a montagem do teste, sendo possível obter a germinação completa nesse período.

\section{CONCLUSÃO}

O teste de germinação de sementes de Apuleia leiocarpa deve ser realizado com papel toalha umedecido 2,$0 ; 2,5$ ou 3,0 vezes a massa do papel seco. A primeira contagem de germinação deve ser realizada no sétimo dia, e a contagem final no $12^{\circ}$ dia após a montagem do teste.

\section{AGRADECIMENTOS}

À Universidade Comunitária da Região de Chapecó (Unochapecó) pelo suporte financeiro à pesquisa e ao Estado de Santa Catarina pela concessão da bolsa de iniciação científica (Artigo 170 da Constituição Estadual).

\section{REFERÊNCIAS}

ALVES, E. U.; SANTOS-MOURA, S. S.; MOURA, M. F.; GUEDES, R. S.; ESTRELA, F. A. Germinação e vigor de sementes de Crataeva tapia L. em diferentes substratos e temperaturas. Revista Brasileira de Fruticultura, Jaboticabal, v.34, n.4, p.1208-1215, 2012.

ALVES, E. U.; GONÇALVES, E. P.; VIANA, J. S.; SANTOS, S. S.; MOURA, M. F. Effect of temperature and substrate on germination of Peltophorum dubium (Sprengel)
Taubert seeds. Acta Scientiarum Biological Sciences, v.33, n.1, p. 113-118, 2011.

ALVARES, C.; STAPE, J. L.; SENTELHAS, P. C.; GONÇALVES, J. L. M.; SPAROVEK, G. Köppen's climate classification map for Brazil. Meteorologische Zeitschrift, Stuttgart, v.22, n.6, p.711-728, 2013.

ANDRADE, A. C. S.; PEREIRA, T. S.; FERNANDES, M. J.; CRUZ, A. P. M.; CARVALHO, A. S. R. Substrato, temperatura de germinação e desenvolvimento pós-seminal de sementes de Dalbergia nigra. Pesquisa Agropecuária Brasileira, Brasília, v.41, n.3, p.517-523, 2006.

BASSACO, M. V. M; NOGUEIRA, A. C; COSMO, N. L. Avaliação da germinação em diferentes temperaturas e substratos e morfologia do fruto, semente e plântula de Sebastiania brasiliensis. Floresta, Curitiba, v.44, n.3, p.381392, 2014.

BEWLEY, J. D.; BRAFORD, K. J.; HILHORST, H. W.M.; NONOGAKI, H. Seeds: Physiology of development, germination and dormancy. 3 ed. New York: Springer, 2013. 392 p.

BIANCHETTI, A.; MARTINS, E. G.; FOWLER, J. A. P.; RAMOS, A.; ALVES, V. F. Tratamentos pré-germinativos para sementes de grapia (Apuleia leiocarpa). Embrapa Florestas - Comunicado Técnico (Infoteca-E), 1995.

BORGES, E. E. L.; TOOROP, P. E. Germinação de sementes. In: PIÑA-RODRIGUES, F. C. M; FIGLIOLIA, M. B; SILVA, A. Sementes Florestais Tropicais: da ecologia à produção. Londrina: ABRATES, 2015. Cap. 4, 244-248p.

BRASIL. Ministério da Agricultura e Reforma Agrária. Regras para Análise de Sementes. Departamento Nacional de Defesa Vegetal. 2 ed. Brasília, 2009. 395p.

BRASIL. Ministério da Agricultura, Pecuária e Abastecimento. Instruções para análise de sementes de espécies florestais. Ministério da Agricultura, Pecuária e Abastecimento. Secretaria de Defesa Agropecuária /Coordenação Geral de Apoio Laboratorial. Brasília, DF: Mapa/SDA/CGAL, 2013. 97 p.

BRASIL. Portaria $n^{\circ} 443$, de 17 de dezembro de 2014. Lista Nacional Oficial de Espécies da Flora Ameaçadas de Extinção. Diário Oficial da União, $n^{\circ} 245,18$ de dezembro de 2014, p. 110- 121, 2014.

CARVALHO, P. E. R. Espécies arbóreas brasileiras. v. 1. Brasília, DF: Embrapa Informação Tecnológica, 2003. 1039 p.

DUARTE, M. M.; FREITAS, M. J. E.; BLUM, C. T.; NOGUEIRA, A. C. Germinação e morfologia de sementes e plântulas de Albizia edwallii (Hoehne) Barneby \& JW Grimes. Revista Caatinga, Mossoró, v. 28, n. 3, p. 166-173, 2015.

Revista Verde, v.13, n.4, p.437-444, 2018 
DUTRA, A. F.; ARAUJO, M. M.; RORATO, D. G.; MIETH, P. Germinação de sementes e emergência de plântulas de Luehea divaricata Mart. et. Zucc. em diferentes substratos. Ciência Florestal, Santa Maria, v.26, n.2, p.411-418, 2016.

FELIPPI, M.; MAFRA, C. R. B.; CNTARELLI, E. B.; ARAÚJO, M. M.; LONGHI, S. J. Fenologia, morfologia e análise de sementes de Apuleia leiocarpa (Vogel) JF Macbr. Ciência Florestal, v. 22, n. 3, p. 477-491, 2012.

FERRAZ, I. D. K. ; CALVIN, G. P. Teste de germinação. In: LIMA JÚNIOR, M. J.; GENTIL, D. F. O.; FIGLIOLIA, M. B.; FERAZ, I. D. K.; CALVI, D. P.; PIÑA-RODRIGUES, M. C. F.; DA SILVA, V. S.; DE SOUZA, M. M. Manual de Procedimentos para Análise de Sementes Florestais. $1^{\text {a }}$ ed., Londrina: ABRATES, 2011. 83p.

FIGLIOLIA, M. B. A pesquisa e o estabelecimento de técnicas para análise de sementes florestais no Brasil. In PIÑA-RODRIGUES, F. C. M; FIGLIOLIA, M. B; SILVA, A. Sementes Florestais Tropicais: da ecologia à produção. Londrina: ABRATES, 2015. Cap. 5, 286-288p.

FLORES, A. V.; ATAÍDE, G. M. de L; BORGES, E. E.; GONÇALVES, L. E. S.; MANFIO, C. E. Umedecimento do substrato e temperatura na germinação de sementes de Melanoxylon brauna Schott. Revista Brasileira de Ciências Agrárias, Recife, v.8, n.3, p.454-457, 2013.

GONÇALVES, E. P.; FRANÇA, P. R. C. de; VIANA, J. S.; ALVES, E. U.; GUEDES, R. S; LIMA, C. R. de Umedecimento do substrato e temperatura na germinação de sementes de Parkia platycephala Benth. Ciência Florestal, Santa Maria, v.25, n.3, p.563-569, 2015.

GRINGS, M.; BRACK, P. Apuleia leiocarpa (Grápia). In: CORADIN, L; SIMINSKI, A; REIS, A. Espécies nativas da flora brasileira de valor econômico atual ou potencial: plantas para o futuro - Região Sul. 1 ed. Brasília: MMA, 2011.Cap 5. 410-413p.

GUEDES, R. S.; ALVES, E. U.; GONÇALVES, E. P.; VIANA, J. S.; FRANÇA, P. R. C.; de LIMA, C. R. de. Umedecimento do substrato e temperatura na germinação e vigor de sementes de Amburana cearensis (All.) A.C. Smith1. Revista Brasileira de Sementes, Londrina, v.32, n.3, p.116$122,2010$.

GUEDES, R. S.; ALVES, E. U. Substrato e temperaturas para o teste de germinação de sementes de Chorisia glaziovii (O. Kuntze). Cerne, Lavras, v.17, n.4, p.525-531, 2011.

JOSÉ, A. C.; COUTINHO, A. B.; ERASMO, E. A. L. Effect of temperature and substrate on the germination of Apuleia leiocarpa (Vogel) JF Macbr (amarelão) seeds. Agrarian, Dourados, v. 4, n. 14, p. 286-293, 2011.

LABORIAU, L. G. A Germinação de Sementes. Washington: OEA, 1983. 174p.

LABOURIAU, L. G.; VALADARES, M. E. B. On the germination of seeds Calotropis procera (Ait.) Ait.f. Anais da
Academia Brasileira de Ciências, Rio de Janeiro, v.48, n.2, p.263-284, 1976.

LIMA, J. D.; ALMEIDA, C. C.; DANTAS, V. A. V.; SILVA, B. M. D. S.; MORAES, W. D. S. Effect of temperature and substrate on seed germination of Caesalpinia ferrea Mart. ex Tul.(Leguminosae, Caesalpinoideae). Revista Árvore, v. 30, n. 4, p. 513-518, 2006.

LIMA, C. R.; PACHECO, M. V.; BRUNO, R. L. A.; FERRARI, C. S.; BRAGA-JÚNIOR, J. M.; BEZERRA, A. K. D. Temperaturas e substratos na germinação de sementes de Caesalpinia pyramidalis tul. Revista Brasileira de Sementes, Rio de Janeiro, v.33, n. 2 p. 216-222, 2011.

LIMA JÚNIOR, M. J.; GENTIL, D. F. O.; FIGLIOLIA, M. B.; FERAZ, I. D. K.; CALVI, D. P.; PIÑA-RODRIGUES, M. C. F.; DA SILVA, V. S.; DE SOUZA, M. M. Manual de procedimentos para análise de sementes florestais. $1^{\mathrm{a}}$ ed. Londrina: ABRATES, 2011. 83p.

LORENZI, H. Árvores Brasileiras: manual de identificação e cultivo de plantas arbóreas nativas do Brasil. São Paulo: Editora Plantarum, 2008. 384 p.

MAGUIRE, J. D. Speed of germination-aid in selection and evaluation for seedling emergence and vigor. Crop Science, Madison, v.2, n.1, p.176-177, 1962.

MARCOS FILHO, J.; CICERO, S. M.; SILVA, W. R. Avaliação da qualidade das sementes. Piracicaba: FEALQ, 1987. 230p.

MARCOS FILHO, J. Fisiologia de sementes de plantas cultivadas. 2 ed. Londrina: ABRATES, 2015. 660p.

MARTINS, C. C.; MACHADO, C. G.; CALDAS, I. G. R.; VIEIRA, I. G. Vermiculita como substrato para o teste de germinação de sementes de barbatimão. Ciência Florestal, Santa Maria, v.21, n.3, p.421-427, 2011.

MARTINS, C. C.; MACHADO, C. G.; SANTANA, D, G. de; ZUCARELI, C. Vermiculita como substrato para o teste de germinação de sementes de ipê-amarelo. Semina, Londrina, v.33, n.2, p.533-540, 2012.

MELLO, J. L. O.; BARBEDO, C. J. Temperatura, luz e substrato para germinação de sementes de pau-brasil (Caesalpinia echinata Lam., Leguminosae Caesalpinioideae). Revista Árvore, Viçosa, v.31, n.4, p.645655, 2007.

MENDES, M. L.; SOBRINHO, S. de P.; LUZ, P. B. da; BARELLI, M. A. A.; NEVES, L. G. Influência do substrato e do nível de umidade sobre a germinação de sementes de paude-balsa. Revista Caatinga, Mossoró, v.23, n.4, p.155-160, 2010 .

MONDO, V. H. V.; BRNCALION, P. H. S.; CICERO, S. M.; NOVEMBRE, A. D. D. L. C.; DOURADO NETO, D. Germination test of seeds of Parapiptadenia rigida (Benth.) Brenan (Fabaceae). Revista Brasileira de Sementes, Londrina, v. 30, n. 2, p. 177-183, 2008. 
OLIVEIRA, A. K. M.; SOUZA, S. A.; SOUZA, J. S.; CARVALHO, J. M. B. Temperature and substrate influences on seed germination and seedling formation in Callisthene fasciculata Mart. (Vochysiaceae) in the laboratory. Revista Árvore, Viçosa, v.39, n.3, p.487-495, 2015.

OLIVEIRA, F. N.; FRANÇA, F. D.; TORRES, S. B.; NOGUEIRA, N. W.; FREITAS, R. M. O. Temperaturas e substratos na germinação de sementes de pereiro vermelho (Simira gardneriana M.R. Barbosa \& Peixoto). Revista de Ciência Agronômica, Fortaleza, v.47, n.4, p.658-666, 2016.

PACHECO, M. V.; ARAÚJO, F. S.; FERRARI, C. S.; BRUNO, R. L. A. Germinação de sementes de Combretum leprosum Mart. Revista Caatinga, Mossoró, v.27, n.1, p.154$162,2014$.

POPINIGIS, F. Fisiologia da Semente. Brasília: Ministério da Agricultura/AGIPLAN, 1985.

RAMOS, M. B. P.; VARELA, V. P.; MELO, M. F. F. Influência da temperatura e da água sobre a germinação de sementes de paricá (Schizolobium amazonicum Huber. Ex. Ducke - Leguminosae-Caesalpinioideae). Revista Brasileira de Sementes, Londrina, v.28, n.1, p.163-168, 2006 a.

RAMOS, M. B. P.; VARELA, V. P.; MELO, M. F. F. Influência da temperatura e da quantidade de água no substrato sobre a germinação de sementes de Ochroma pyramidale (Cav. ex Lam.) Urban (pau-de-balsa). Acta Amazônica, Manaus, v.36, n.1, p.103-106, 2006 b.

ROCHA, C. R. M.; COSTA, D. S.; NOVEMBRE, A. D. L. C.; CRUZ, E. D. Morfobiometria e germinação de sementes de Parkia multijuga Benth. Nativa, Sinope, v.2, n.1, p.42-47, 2014.

SANTOS, S. R. G.; AGUIAR, I. B. Germinação de sementes de branquilho (Sebastiania commersoniana (Baill.) Smith \& Downs) em função do substrato e do regime de temperatura. Revista Brasileira de Sementes, Londrina, v.22, n.1, p.120126, 2000.

SILVA, F. A. S.; AZEVEDO, C. A. V. de. The Assistat Software Version 7.7 and its use in the analysis of experimental data. African Journal of Agricultural Research, v.11, n.39, p.3733-3740, 2016.

SPADETO, C.; LOPES, J. C.; MENGARDA, L. H. G.; MATHEUS, M. T.; BERNARDES, P. M. Estresse salino e hídrico na germinação de sementes de garapa (Apuleia leiocarpa (VOGEL.) JF Macbr.). Enciclopédia Biosfera, Goiânia, v.8, n.14, p.539-551, 2012.

VARELA, V. P.; RAMOS, M. B. P.; MELO, M. de F. F. Umedecimento do substrato e temperatura na germinação de sementes de angelim-pedra (Dinizia excelsa Ducke). Revista Brasileira de Sementes, Londrina, v.27, n.2, p.130-145, 2005.

WIELEWICKI, A. P.; LEONHARDT, C.; SCHLINDWEIN, G.; MEDEIROS, A. C. S. Proposta de padrões de germinação e teor de água para sementes de algumas espécies florestais presentes na Região Sul do Brasil. Revista Brasileira de Sementes, 2006, 28, 191-197. 